\title{
A step up for geoengineering
}

\author{
The clock is ticking for climate change mitigation. Geoengineering is gaining ground as an option, but it \\ needs to be examined at a large scale to determine its effectiveness and associated risks.
}

On the 4th of November the Paris Agreement came into effect. Over one hundred countries have agreed to keep warming below $2^{\circ} \mathrm{C}$ above pre-industrial levels (and ideally at no more than $1.5^{\circ} \mathrm{C}$ ) to avoid dangerous climate change. This is only the first step in a long and challenging journey that awaits humankind. We have just experienced the hottest five-year period on record globally ${ }^{1}$ and 2016 is looking set to become the warmest year on record too ${ }^{2}$. As a result, we are edging close to $1.2^{\circ} \mathrm{C}$ already. As noted in a commentary by Parker and Geden on page 859 of this issue, to achieve the ambitious $1.5^{\circ} \mathrm{C}$ target, reducing fossil fuel emissions will not be enough. We will need to explore all available options, including the removal of $\mathrm{CO}_{2}$ directly from the air as well as a variety of geoengineering proposals that fix temperature change only.

Geoengineering is controversial for two main reasons. First, concentrating on technological fixes could detract from mitigating the causes of climate change ${ }^{3}$, and second, the side effects of further tampering with the Earth system are unclear. The first point is reminiscent of the climate change adaptation debate 15 years or so ago. At the time, adaptation was almost a taboo topic, so as not to take the focus away from mitigation. Then it became clear that the world was already on a path to substantial climate change ${ }^{4}$, which we would need to adapt to no matter what. And so the discourse softened. Today, it is hard to imagine that adaptation was not always a mainstream component in the effort to address climate change. A similar turning point for geoengineering may arise from the Paris Agreement: the agreement brings new clarity to the now insurmountable gap between necessary, and realistically possible emission cuts. Like adaptation in the mid-2000s, geoengineering is about to move from being seen as an option that competes with mitigation to becoming a parallel wedge in the effort to uphold the targets set in Paris ${ }^{5}$.

That leaves the second objection: the side effects. These are different for two types of geoengineering. On the one hand, various proposals on solar geoengineering exist to cool the planet by reflecting more sunlight. On the other hand, much research has been done into removing $\mathrm{CO}_{2}$ from the exhaust fumes of fossil fuel combustion or directly from the air, to sequester it underground or on the seafloor.

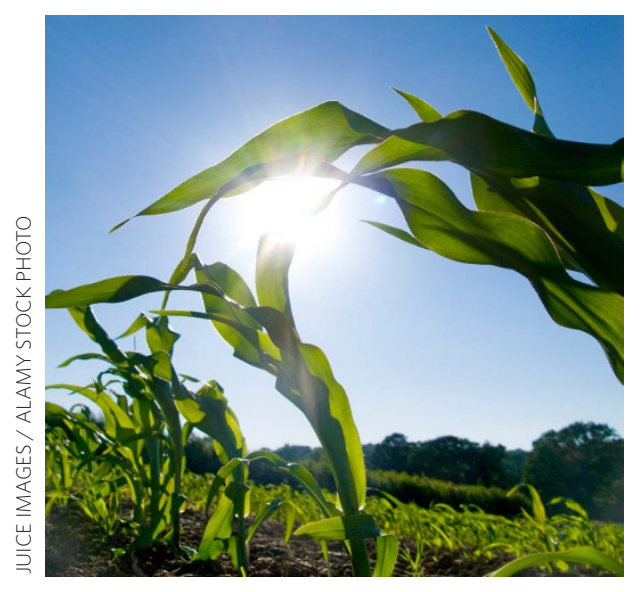

Assessing the risks associated with these proposals is imperative. Accordingly over the past decade, geoengineering has become a field of research in its own right ${ }^{6}$.

One of the most prominent proposals in solar geoengineering is the injection of sulfate particles into the upper atmosphere to reduce the amount of incoming sunlight. Essentially, this does not reduce the build-up of greenhouse gases in the lower reaches of the atmosphere, but instead it adds a second, cooling layer in the hope that the effects on climate more or less cancel out. If, however, this does not happen, or if the second layer suddenly deteriorates, the impacts could be severe. Nevertheless, with a scarcity of viable options at hand, Parker and Geden argue that solar geoengineering must neither be treated as taboo, nor furtively used to make the model outcome look more optimistic in the upcoming Special Report of the Intergovernmental Panel on Climate Change on $1.5^{\circ} \mathrm{C}$. What we need instead is a critical scientific assessment of the utility and risks associated with solar radiation management.

In the second class of geoengineering options, carbon capture and storage features prominently. The idea is to capture $\mathrm{CO}_{2}$ released during power generation and inject it into reservoirs under the land ${ }^{7}$ or seabed, where it can remain locked on geological timescales. The main risks are associated with leakage, and the challenge lies with detecting and quantifying any leaks. Stopping a leak, once it is detected, is expected to reverse its environmental impact swiftly $^{8}$. To assess leakage risks in a realworld environment, next year a controlled
$\mathrm{CO}_{2}$ release experiment will take place offshore from Scotland in the North Sea to test our ability to monitor and detect leaks over large areas (http://www.stemm-ccs.eu/).

Removing $\mathrm{CO}_{2}$ directly from the air is, ultimately, the only way to reduce atmospheric concentrations, as opposed to just slowing their increase, and in this context enhanced weathering is being investigated. Farmers have long been adding crushed basalt to crops as fertilizer. After all, basalt rocks help make volcanic regions so productive. Application of these rocks to agro-ecosystems on a large scale has the potential to significantly enhance the natural weathering process that draws $\mathrm{CO}_{2}$ from the atmosphere and eventually leaves the carbon locked up in carbonates in the seafloor ${ }^{9}$.

On this option, too, large-scale experiments are afoot. From next year onwards, enhanced weathering will be investigated in a special facility in Illinois, US, in four hectares of corn fields over a period of ten years - a big step up from current modelling studies and small laboratory experiments ${ }^{10}$. The risks of this option seem limited and no significant investment in infrastructure is needed, but social acceptance and the energy required to pulverize so much basalt needs to be factored in.

The shift to larger scale experiments is encouraging, but may not be sufficient in light of the urgency of reducing greenhouse gas levels. If we are serious about averting dangerous climate change we need to have all the options on the table, and as soon as possible, with a realistic quantification of their potential contribution and associated risks. We know already that restoring planetary balance will require a portfolio of actions, the first of which must be reducing fossil fuel emissions.

\footnotetext{
References

1. The global climate 2011-2015: heat records and high impact weather. World Meteorological Organization (8 November 2016).

2. Provisional WMO statement on the status of the global climate in 2016. World Meteorological Organization (14 November 2016).

3. Anderson, K. \& Peters, G. Science 354, 182-183 (2016).

4. Wigley, T. Science 307, 1766-1769 (2005).

5. Lackner, K. S. et al. Science 354, 714 (2016).

6. Shepherd, J. G. Phil. Trans. R. Soc. A 370, 4166-4175 (2012).

7. Matter, J. M. et al. Science 352, 1312-1314 (2016).

8. Blackford, J. et al. Nat. Clim. Change 4, 1011-1016 (2014)

9. Taylor, L. L. et al. Nat. Clim. Change 6, 402-406 (2016).

10. $£ 10$ million Leverhulme Centre for Climate Change Mitigation at University of Sheffield announced. The University of Sheffield (2 December 2015); http://go.nature.com/2fIJgdA
} 